\title{
La exclusión en el cómputo del cálculo de la legítima de la donación o legado del derecho de habitación a favor de persona con discapacidad
}

\section{A exclusão da doação ou legado de direito de habitação em favor da pessoa com deficiência do cálculo da legítima}

\section{The exclusion of the donation or legacy of housing rights in favor of the disabled person from the calculation of legitimate}

Pedro Botello Hermosa* Victoriano Gallego Arce ${ }^{* *}$

\section{Resumen}

La ley 41/2003 de protección patrimonial de las personas con discapacidad debe ser considerada como una de las normas más importantes aprobadas en el ámbito del Derecho Sucesorio español en los últimos años. Una de sus novedades más importantes fue el hecho de que las donaciones o los legados de un derecho de habitación a favor de personas con discapacidad no se computarán para el cálculo de las legítimas si en el momento del fallecimiento ambos estuviesen conviviendo en ella.

Palabras Claves: Ley de Protección Patrimonial de las Personas con Discapacidad. Derecho Sucesorio español. Derecho de habitación.

\section{Resumo}

A Lei 41/2003, de proteção patrimonial das pessoas com deficiência, deve ser considerada uma das normas mais importantes aprovadas no âmbito do Direito Sucessório espanhol nos últimos anos. Uma das suas novidades mais importantes foi a exclusão da doação ou legado de direito de habitação em favor da pessoa com deficiência para o cálculo das legítimas se, no momento do falecimento, ambos estivessem a conviver com ela.

Palavras-chave: Lei de Proteção Patrimonial das Pessoas com Deficiência. Direito Sucessório espanhol. Direito de habitação.

\section{Abstract}

The law 41/2003 of patrimonial protection of disabled people must be considered like one of the most important norms approved in the field of the Spanish Sucessory Right in the last years. One of its most important novelties was the fact that the donations or legacies of a room right in favor of disabled people will not be computed for the calculation of the legitimate ones if at the time of death both were living together in it.

Keyword: Law of Patrimonial Protection of Persons with Disabilities. Spanish Succession Law. Right of room.

Doctor por la Universidad de Sevilla. Profesor del Centro San Isidoro, Adscrito a la Universidad Pablo de Olavide de Sevilla. Sevilla - Espanha. E-mail: pedrobh4@gmail.com.

Doctor por la Universidad de Sevilla. Profesor del Centro San Isidoro, Adscrito a la Universidad Pablo de Olavide de Sevilla. Sevilla - Espanha. E-mail: vgallego@ceade.es 


\section{Introducción}

La Ley 41/2003, ${ }^{1}$ de 18 de noviembre, de Protección Patrimonial de las Personas con Discapacidad y de modificación del Código Civil, ${ }^{2}$ de la Ley de Enjuiciamiento Civil y de la Normativa Tributaria con esta finalidad, ${ }^{3}$ destaca tanto por la gran importancia que ha adquirido dentro del Ordenamiento jurídico español, como por el gran número de interrogantes jurídicos que su deficiente redacción técnico-jurídica plantea.

Lo cierto es que la gran importancia de la LPPD se refleja ya en las normas que dicha ley modificó tras su publicación, como son el C.c., la Ley de Enjuiciamiento Civil y la normativa tributaria que tenga por finalidad la protección de las personas con discapacidad.

Uno de los mayores méritos de la LPPD fue otorgar carta de naturaleza a las personas con discapacidad, las cuales, hasta ese momento, no tenían cabida en el Ordenamiento jurídico español al no estar contempladas en nuestros textos legales (sólo lo estaban las personas plenamente capaces y las personas incapacitadas judicialmente ${ }^{4}$ ).

¿Qué reconocimiento jurídico tenían entonces en el C.c. todas aquellas personas con una discapacidad reconocida administrativamente, que no habían pasado por el procedimiento de incapacitación?

Pues aunque resulte sorprendente, hasta la publicación de la LPPD ninguno.

De hecho, fue precisamente esta ley la que introdujo en nuestro C.c. una nueva Disposición Adicional (la cuarta) que se suma a las tres existentes desde su promulgación en 1.889, consiguiendo que desde entonces también se hablase de las personas con discapacidad dicho cuerpo legal, exponiendo la Disposición Adicional cuarta que

La referencia que a personas con discapacidad se realiza en los arts. 756, 822 y 1.041, se entenderá hecha al concepto definido en la Ley de protección patrimonial de las personas con discapacidad y de modificación del Código civil, de la Ley de Enjuiciamiento Civil y de la normativa tributaria con esta finalidad.

Leña Fernández (2005, p. 183), al referirse a la LPPD, considera que

[...] desde el punto de vista técnico-jurídico, la Ley es muy imperfecta, con demasiadas imprecisiones, lagunas clamorosas y una evidente cortedad de alcance en las soluciones planteadas, lo que ha llevado a SEDA HERMOSÍN a calificarla, como un verdadero parto de los montes. No era así en su primer anteproyecto, pero, sin duda, las sucesivas y numerosas manos (y mentes) puestas sobre ella han conseguido realizar este verdadero estropicio.

Bien, pues, a pesar de todo eso, o mejor, por encima de todo eso, creo que hay que saludarla como un avance importante en lo que hace referencia al entorno jurídico del discapacitado, y ello, porque abre espacios de libertad en ese entorno, unos espacios de libertad que permiten una mayor igualación, sobre todo en el ámbito patrimonial, con los plenamente capaces y que llevamos reclamando, desde hace ya bastantes años, algunos de los que nos venimos ocupando de estas materias. [...] Por eso mi posición, respecto a ella y por encima de sus muchas imperfecciones e insuficiencias formales y materiales, es sumamente favorable: aprecio en ella su apertura a espacios de libertad.

Publicada en el B.O.E. núm. 277, de 19 noviembre de 2003.

En adelante C.c.

En adelante LPPD.

Término el de personas incapacitadas con las horas contadas en nuestro ordenamiento, ya que el cambio terminológico se ha producido en algunas leyes, como las mencionadas la Ley 20/2011 y Ley Orgánica 2015 de modificación del Código Penal., aunque por encima de todas debemos destacar lo ocurrido en la Ley 15/2015, de 2 de julio, de la Jurisdicción Voluntaria, donde directamente se hace referencia al procedimiento de la incapacitación como "proceso judicial para modificar la capacidad de una persona", y a la persona incapacitada como "persona con capacidad modificada judicialmente", mientras que al mismo tiempo sigue regulando las figuras de la tutela, la curatela y el guardador de hecho. 
En cuanto a su importancia, González Porras (2005, p. 699-700) cuenta que

[...] la reforma llevada a cabo por la Ley $41 / 2.003$, de 18 de Noviembre, que lleva el título de Ley de Protección Patrimonial de las Personas con Discapacidad [...], es, a mi juicio, una de las más importantes, si no la de mayor calado entre las que han reformado el articulado de nuestro Código civil, y diré que pienso que es así porque afecta de manera directa a los tres pilares fundamentales del 'Sistema', que son 'la persona física' y además la persona física discapacitada, primer elemento sobre el que se apoya el Derecho civil [...], 'La familia' [...], y el 'patrimonio' como factor necesario para su desarrollo.

Ateniéndonos a su Exposición de Motivos, ${ }^{5}$ la LPPD tiene por objeto

regular nuevos mecanismos de protección de las personas con discapacidad, centrados en un aspecto esencial de esta protección, cual es el patrimonial. Efectivamente, uno de los elementos que más repercuten en el bienestar de las personas con discapacidad es la existencia de medios económicos a su disposición, suficientes para atender las específicas necesidades vitales de los mismos.

Y es que, tal y como afirma Gómez Gálligo (2005, p. 11), el dinero no es la felicidad pero ayuda a ella. Esta afirmación podríamos suscribirla todos los ciudadanos, cualquiera que sea nuestro sexo o nuestra condición social. Sin embargo, es especialmente cierta cuando tenemos alguna discapacidad física o psíquica. Cierto es que el dinero no lo es todo: los discapacitados necesitan (necesitamos, podríamos decir, pues cualquiera de nosotros puede pertenecer a ese colectivo en cualquier momento) cariño, asistencia, supresión de barreras arquitectónicas, apoyo, comprensión, paciencia... Pero también medios económicos. Sólo así puede hacerse efectivo el principio constitucional de igualdad ante la ley: tratando desigualmente situaciones desiguales.

De ahí que el único objetivo de la LPPD sea, como su propio nombre indica, la protección patrimonial de las personas con discapacidad (e incapacitadas, aunque su título no lo refleje, ya que este es el colectivo de personas que exclusivamente protege la que en mi opinión es la medida más importante introducida por la norma en nuestro Derecho Sucesorio, como es el nuevo alcance otorgado a la sustitución fideicomisaria).

Una de las principales preocupaciones de los progenitores de las personas con discapacidad, y de las incapacitadas judicialmente, será quién se ocupará de ellos una vez que su responsable fallezca. A este respecto, expone Vivas Tesón (2009, p. 8) que

[...] dicha Ley permite prever y planificar el bienestar económico de las personas con discapacidad, adoptando soluciones de protección patrimonial que, en el futuro, puedan, eficazmente, complementar los ingresos económicos que ellas mismas obtengan por su trabajo o por pensiones públicas de diversa índole y, por consiguiente, permitirle vivir una mejor vida adulta. No es preciso esperar a formularse angustiosamente la pregunta: “¿Qué será de él/ella cuando no pueda hacerme cargo o me muera?, para iniciar la planificación económica de su etapa adulta, pues este proyecto de futuro puede comenzarse desde la niñez o adolescencia de la persona con discapacidad, contando, incluso, para ello, como tendremos ocasión de ver, con algunas ventajas fiscales.

Es precisamente una de estas medidas implementadas en nuestro Ordenamiento por la LPPD con la intención de proteger patrimonialmente a las personas con discapacidad la que centra el objeto del presente artículo: la donación o el legado del derecho de habitación a favor de las personas con discapacidad.

\section{Donaciones y legados del derecho de habitación a favor de personas con discapacidad}

Existen normas tanto en la Ley de Arrendamientos Urbanos como en la Ley de Propiedad Horizontal, encaminadas a atender las necesidades de las personas con algún tipo de discapacidad en cuanto a la adecuación de su vivienda, entiéndase, por ejemplo, su accesibilidad.

\footnotetext{
5 En adelante EM.
} 
Sin embargo, lo que se consiguió tras la promulgación de la LPPD fue la protección de las personas con discapacidad mediante la adjudicación del uso de una vivienda sin que nadie pueda arrebatárselo bajo ningún concepto.

Para ello se le otorgó una redacción completamente nueva al art. 822 del C.c., y convirtiéndose el antiguo artículo 822 del C.c. en el párrafo tercero del artículo 821.

El estudio del presente artículo 822 lo realizaré por epígrafes dado su amplitud, así como por el interés de cada uno de los párrafos.

Recoge el primer párrafo del actual artículo 822 del C.c. que "La donación o legado de un derecho de habitación sobre la vivienda habitual que su titular haga a favor de un legitimario persona con discapacidad, no se computará para el cálculo de las legítimas si en el momento del fallecimiento ambos estuvieren conviviendo en ella".

De este primer párrafo del precepto podemos destacar dos figuras jurídicas interesantes a las que merece la pena hacer referencia, como son:

$1^{\text {a }}$.-La donación de un derecho de habitación a favor de una persona con discapacidad. Nos encontramos ante una donación ordinaria, ${ }^{6}$ o lo que es lo mismo, una donación inter vivos, por lo que la donación tendrá que ser aceptada por el donatario o su representante legal mediante escritura pública, produciéndose sus efectos legales desde el momento de la firma.

Eso sí, la doble mención en el art. 822 del C.c. de donación o legado hace que asimilemos la figura a la clase de donaciones en la que la entrega se realice post mortem, admitiéndose, por tanto, en este caso la posibilidad de las donaciones mortis causa, o lo que es lo mismo, las donaciones recogidas en el art. 620 C.c.. ${ }^{7}$

$2^{\circ}$.- El legado de un derecho de habitación a favor de una persona con discapacidad que el testador puede otorgar en su testamento. Como sabemos, en el legado del derecho real de habitación el legatario adquiere el derecho legado desde la muerte del testador, si bien tiene que pedir la entrega de la posesión al gravado o gravados con el legado.

Lo cierto es que ambas figuras, tanto la donación como el legado del derecho de habitación especial que posibilita el art. 822 del C.c., necesitan del cumplimiento de una serie de requisitos para surtir efectos, requisitos en los cuales pasamos a centrarnos a continuación:

\subsection{Legitimario con discapacidad como posible beneficiario}

Es necesario que el donatario o legatario del derecho de habitación sea un legitimario del causante, pero no un legitimario cualquiera, sino uno que tenga la consideración de persona con discapacidad.

De esta primera exigencia destaca, por una parte, que el donatario o legatario ha de ser una persona con discapacidad, ${ }^{8}$ y por otra se exige al donatario o legatario ser legitimario del testador, por lo que no sólo alcanzará a los hijos o descendientes con discapacidad (como sucede, por ejemplo, en la nueva sustitución fideicomisaria introducida por la LPPD), sino que, además de ellos, serán posibles beneficiarios de esta medida de protección, tanto los padres o ascendientes, como el cónyuge viudo.

6 Como afirma Diaz Alabart (2004, p. 863-864), "Creo que verdaderamente es así, y que en ningún caso se trataría de una donación mortis causa, en el supuesto de que éstas verdaderamente existan en nuestro Derecho. Si bien no voy a entrar de lleno en la cuestión por ser, a mi entender, ajena a la cuestión que estoy tratando en estas páginas, si querría recordar algunos extremos. En la opinión de la mayor parte de los autores (entre los que me incluyo), y la jurisprudencia, a tenor del art. $620 \mathrm{CC}$ las donaciones mortis causa no existen como tales donaciones puesto que <<participan de la naturaleza de las disposiciones de última voluntad y se regirán por las reglas establecidas para la sucesión testamentaria. (...)".

Establece el artículo 620 del C.c.: "Las donaciones que hayan de producir sus efectos por muerte del donante participan de la naturaleza de las disposiciones de última voluntad, y se regirán por las reglas establecidas para la sucesión testamentaria".

8 O lo que es lo mismo, que sufra y tenga acreditada una minusvalía psíquica igual o superior al 33 por ciento o una minusvalía física o sensorial, igual o superior al 65 por ciento. 
Particularmente soy partidario de que la interpretación que hay que dar al art. 822 en cuanto a que la donación se haga a favor de un legitimario persona con discapacidad, sea una interpretación lo más amplia posible ${ }^{9}$ en el sentido de que pueda verse favorecido por este nuevo derecho de habitación cualquier legitimario, aunque no sea legitimario efectivo, oponiéndome con ello a que se siga el régimen general de las atribuciones a título gratuito ${ }^{10}$ (los legitimarios más próximos excluyen a los de siguiente grado).

Con ello se evitaría, por ejemplo, la situación absurda de que un nieto con discapacidad cuyo padre viviese (sería éste el legitimario), no pudiese verse beneficiado de tal derecho aunque esa fuese la voluntad de su abuelo simplemente por no ser legitimario del causante. Lo mismo ocurriría con el padre con discapacidad del testador que por tener hijos no puede proteger mediante esta medida al padre con discapacidad.

\subsection{La vivienda habitual como objeto del derecho de habitación legado o donado}

También exige el primer párrafo del artículo 822 del C.c. que el derecho de habitación donado o legado tenga por objeto la vivienda habitual, y de ahí que dicho derecho no surtirá efecto cuando la donación o el legado del derecho de habitación a persona legitimaria con discapacidad se produzca sobre otra vivienda del causante que no sea la habitual. ${ }^{11}$

Considero que no está muy acertado el legislador al restringir exclusivamente la nueva donación o legado de habitación "sobre la vivienda habitual", ya que, con ello, puede perjudicar sin ninguna necesidad tanto a la propia persona con discapacidad, como al resto de colegitimarios. Imaginemos, por ejemplo, el caso en el que el causante vive con su familiar con discapacidad en una casa muy grande y decide donarle o legarle otro piso más pequeño pero igualmente habilitado para éste. Con tal donación o legado perjudicaría mucho menos al resto de colegitimarios en cuanto a su legítima estricta, ya que, entonces, sí se computaría sobre este tercio de legítima la casa grande donde en su día convivieron causante y beneficiado con discapacidad, sin que por ello se esté perjudicando a este último, el cual igualmente se vería beneficiado por la nueva figura introducida por la LPPD.

Por ello, y ateniéndonos a la literalidad del art. 822 C.c., entiendo que el causante que quiera proteger a su familiar con discapacidad se ve obligado a donarle o legarle el derecho de habitación sobre la vivienda habitual, no pudiendo por tanto elegir libremente sobre qué inmueble decide otorgar tal derecho, pudiendo perjudicar tal situación a la propia persona con discapacidad, ya que en el ejemplo anterior no sería de extrañar que el testador, por no perjudicar al resto de colegitimarios (que pueden, por qué no, estar igual o más necesitados que la persona con discapacidad) decida finalmente no otorgar el derecho de habitación a su favor sobre la vivienda habitual.

Por último, considero que el legislador, como mínimo, podría haber especificado qué se entiende por "vivienda habitual" para este tipo de supuestos, ya que imaginemos el caso de un testador que pasa 7 meses al año en la casa de la playa y 5 en la casa de la ciudad. ¿Podría en este supuesto el testador donar o legar exclusivamente a favor del familiar con discapacidad el piso de la playa aún siendo más conveniente para éste el piso sito en la ciudad?

Tal idea viene reforzada con lo que expone la EM de la LPPD en su apartado VII, c), que se reforma el artículo 822 del C.c., dando una protección patrimonial directa a las personas con discapacidad mediante un trato favorable a las donaciones o legados de un derecho de habitación [...].

10 En tal sentido, Serrano García (2008, p. 491-492) comenta que: "El donatario o legatario tiene que ser un discapacitado con derecho a legítima (descendiente, ascendiente o cónyuge); no cabe por vía de este legado el derecho de habitación sobre la vivienda habitual al nieto, viviendo el hijo (el padre es el legitimario, y no el nieto)".

11 Como señala Diaz Alabart (2006, p. 2127): "Por tanto la excepción del art. 822 CC no será aplicable cuando el derecho de habitación se constituya respecto a una segunda vivienda que se utiliza en periodo vacacional por más que en ella convivan durante ese tiempo disponente y discapacitado y el fallecimiento del primero se produzca durante dicho periodo". 


\subsection{La convivencia exigida entre causante y beneficiario}

En cuanto a la exigencia impuesta por el legislador de la LPPD de que para poder beneficiarse de este derecho la persona con discapacidad ha de convivir con el testador, no puedo más que discrepar de esta decisión.

Principalmente por dos motivos:

El primero, porque restringe mucho las posibilidades de los familiares con discapacidad del testador de verse beneficiados por el derecho de habitación especial, ya que por ejemplo, un abuelo no podrá beneficiar a un nieto con discapacidad con el derecho de habitación sobre el inmueble que considere si no vivían juntos

Y el segundo, aún más importante, porque coincidiendo con Vivas Tesón (2009, p. 175), considero que la exigencia legal de convivencia de la persona con discapacidad en el domicilio sobre el que se constituye dicho derecho va en contra de su vida autónoma e independiente, siendo precisamente ésta una de las finalidades de la Convención de Naciones Unidas de 13 de Diciembre de 2006 sobre los derechos de las personas con discapacidad.

Imaginemos el caso de personas con audición o vista muy reducida que lleguen a alcanzar el grado de discapacidad del 65 por ciento. ¿Qué lógica tendría exigirles vivir con los familiares para poder verse favorecidos por el nuevo derecho de habitación? O, ¿por qué esta persona si vive con el familiar se podrá ver favorecido, y si no vive con él no? ¿Acaso no tiene el mismo grado de discapacidad?

Tal vez con la redacción del artículo 822 lo que pretende el legislador de 2003 es establecer esta medida de protección sólo y exclusivamente a favor de las personas que sufren una discapacidad tan severa que les impida desarrollar una vida autónoma e independiente.

\subsection{Su condición de legado legal o por ministerio de la ley}

Pero si el primer párrafo del art. 822 del C.c. aporta una serie de figuras jurídicas interesantes, el segundo párrafo recoge una de las novedades más importantes introducidas en nuestro Ordenamiento jurídico por la LPPD, como es el "legado legal" del derecho de habitación sobre la vivienda habitual.

Expone el segundo párrafo del artículo 822 que "Este derecho de habitación se atribuirá por ministerio de la ley en las mismas condiciones al legitimario discapacitado que lo necesite y que estuviera conviviendo con el fallecido, a menos que el testador hubiera dispuesto otra cosa o lo hubiera excluido expresamente, pero su titular no podrá impedir que continúen conviviendo los demás legitimarios mientras lo necesiten".

Es decir, que siempre que la persona con discapacidad lo necesite es la propia ley la que atribuye tal derecho de habitación y con el mismo trato de favor que cuando este derecho tiene su origen en la voluntad del testador, es decir, sin que su valor se compute a la hora de calcular las legítimas.

Sin embargo, estando a la redacción dada por el legislador del art. 822 párrafo $2^{\circ}$, nos encontramos con que el derecho de habitación por ministerio de la ley sólo podrá aplicarse cuando, aparte de la conditio iuris de la convivencia, se cumpla una triple condición:

\section{$1^{\text {a }}$.- Que el legitimario con discapacidad necesite la vivienda.}

Como era de esperar, el legislador no ha determinado el significado del concepto jurídico "necesidad", por lo que considero que se refiere a que no disponga de otro alojamiento, ni de recursos económicos que le permitan acceder a otra vivienda (ya sea mediante arrendamiento o adquiriéndola).

Me planteo si dicha "necesidad" se exige también en los casos en los que sea el propio causante quien done o legue el derecho de habitación (art. 822, párrafo $1^{\circ}$ ), si bien entiendo que no, y que una persona con discapacidad que disponga de otros bienes puede ser igualmente beneficiada con el derecho de habitación sobre el inmueble en el que convivía con el testador, siempre que ésta fuese la voluntad del causante. 
Soy consciente de admitir tal posibilidad supone que el testador grave al resto de colegitimarios respecto de su legítima, si bien esto se produce en aras de favorecer a una persona con discapacidad, cumpliéndose con ello con la finalidad de la LPPD.

$2^{\mathrm{a}}$.- Que el testador no haya excluido expresamente el legado legal al que nos referimos, o haya dispuesto otra cosa. Por tanto, la voluntad del testador no está tan ausente, ya que podía haberse opuesto mediante una manifestación o disposición en el testamento para prohibir la posibilidad del legado legal.

$3^{a}$ El legitimario con discapacidad titular del derecho de habitación no podrá impedir que continúen conviviendo con él en el inmueble los demás legitimarios mientras lo necesiten. Con este último límite el legislador intenta salvaguardar un poco más la figura del legitimario que se verá gravado con la introducción del nuevo legado legal de habitación especial que introduce la LPPD, el cual ya experimenta un perjuicio como consecuencia de no computar el legado del derecho de habitación para el cálculo de las legítimas, como para que, además, se le pueda obligar a abandonar inmediatamente la que también viene siendo su vivienda habitual.

Pero llegados a este punto parece lógico que nos planteemos si esta obligatoriedad de convivir con el resto de legitimarios mientras lo necesiten rige también si el derecho de habitación fue establecido directamente por el testador.

Aunque algunos autores mantienen que sí, ${ }^{12}$ personalmente considero que no es así, ya que de haber sido ésta la verdadera intención del legislador entiendo que hubiese podido acabar el párrafo $1^{\circ}$ del art. 822 tal y como acaba el $2^{\circ}$, es decir, "[...] pero su titular no podrá impedir que continúen conviviendo los demás legitimarios mientras lo necesiten".

Eso sí, queda claro que la persona con discapacidad que disfruta del derecho de habitación por ministerio de la ley ${ }^{13}$ no puede impedir que continúen conviviendo con ella en la vivienda los demás legitimarios "mientras" lo necesiten, ¿pero qué ocurrirá cuando ya no lo necesiten por disponer, por ejemplo, de recursos económicos para resolver el problema del alojamiento? ¿Podrán entonces las personas con discapacidad beneficiadas del legado legal del derecho de habitación exigir al resto de legitimarios el abandono de la vivienda?

El tercer y cuarto párrafo del art. 822 establece que "El derecho a que se refieren los dos párrafos anteriores será intransmisible. Lo dispuesto en los dos primeros párrafos no impedirá la atribución al cónyuge de los derechos regulados en los arts. 1406 y 1407 de este Código que coexistirán con el de habitación".

Tanto el derecho de habitación que tiene su origen en actos voluntarios del titular de la vivienda, como el que atribuye directamente la ley, son intransmisibles, por lo que el legitimario con discapacidad no puede transmitir tal derecho ni por actos inter vivos, ni por actos mortis causa, si bien, antes de esta declaración expresa del párrafo $3^{\circ}$ del art. 822 del C.c., ya el art. 525 del mismo Código establece con carácter general para todo derecho de habitación su intransmisibilidad.

En cuanto a lo recogido en el cuarto y último párrafo del art. 822 del C.c., sobre que los derechos del cónyuge viudo recogidos en los arts. $1.406^{14}$ y $1.407^{15}$ del C. c., coexistirán con el derecho de habitación del legitimario con discapacidad, coincido con Ruíz-Rico Ruíz Morón (2006, p. 386) al considerar que si el cónyuge supérstite opta por la atribución de la propiedad de la vivienda, será dueño exclusivo de ella, pero

\footnotetext{
Como Fuenteseca Degenefee (2004, p. 1758).

Que es un derecho vitalicio, mientras que el otorgado por el causante puede ser temporal, dependiendo de la voluntad de éste

Art.1406 del C.c.: "Cada cónyuge tendrá derecho a que se incluyan con preferencia en su haber, hasta donde éste alcance: [...] $4^{\circ}$ En caso de muerte del otro cónyuge, la vivienda donde tuviese la residencia habitual.".

15 Art.1407 C.c.: "En los casos de los números 3 y 4 del artículo anterior podrá el cónyuge pedir, a su elección, que se le atribuyan los bienes en propiedad o que se constituya sobre ellos a su favor un derecho de uso o habitación. Si el valor de los bienes o el derecho superara al de haber del cónyuge adjudicatario deberá éste abonar la diferencia en dinero".
} 
soportando el gravamen que representa el derecho de habitación de la persona con discapacidad; y si se decide por la constitución a su favor de un derecho de uso o de habitación sobre la vivienda habitual, podrá seguir ocupando ésta, con carácter vitalicio, juntamente con la persona con discapacidad.

Por otro lado, puede darse el caso de que la persona con discapacidad a quien se pretenda favorecer sea el propio cónyuge supérstite, el cual ya tenía por ley la preferencia de disfrute de la vivienda, si bien, tras el nuevo art. 822 C.c., este derecho de habitación no se computará en su haber hereditario, viéndose con ello igualmente favorecido.

\subsection{Su exención del cómputo del cálculo de las legítimas}

Por último, paso a valorar el contenido de la ventaja que concede el art. 822 del C.c. a la persona con discapacidad cuando establece que el derecho de habitación concedido (bien sea por donación, legado o por ministerio de la ley) "no se computará para el cálculo de las legítimas".

Partiendo de la base de que por computar su valor debemos entender traer a la masa hereditaria las liberalidades hechas en vida por el causante para sumarlo al valor de los bienes que deja a su muerte, considero que tampoco está muy acertado el legislador de la LPPD en tal sentido en la nueva redacción dada del art. 822, ya que, si bien es cierto que en lo referente a las donaciones sí se computan para el cálculo de las legítimas, no sucede lo mismo para los legados.

En cuanto a la donación, recoge el art. $818^{16}$ del C.c., que la suma de lo que queda a la muerte del testador y el valor de las donaciones (colacionables) hechas en vida constituye la base para calcular la cuota legitimaria, por lo que las donaciones habrán de ser traídas a la masa hereditaria para computar su valor. Pero a raíz de la entrada en vigor de la LPPD, con la donación de ese especial derecho de habitación que se recoge en el art. 822 sucede lo contrario, es decir, dicha donación no tendrá que ser traída a la herencia para computar su valor, quedando su cuantía excluida del cálculo de las legítimas, por lo que nunca podrán entenderse como inoficiosas al quedar fuera de los bienes y derechos sujetos a los límites de las legítimas.

En cambio, al referirnos a los legados hay que tener en cuenta que tienen un régimen diferente al de las donaciones, ya que, como sabemos, éstos no se computan para el cálculo de las legítimas por formar directamente parte del caudal relicto, sino que, a petición de los herederos forzosos, se reducen si menguan la legítima como establece el art. 817 C.c.. ${ }^{17}$

Aun así queda claro que el legislador, bien sea mediante legado o donación, lo que pretende es que el derecho de habitación concedido a la persona con discapacidad quede fuera de las reglas de la legítima, por lo que el beneficiado, por una parte, disfrutará de dicho derecho de habitación, y, por otra, le corresponderá la misma porción de legítima estricta que al resto de colegitimarios, pudiendo ser independientemente beneficiado con el tercio de mejora y el de libre disposición.

Literalmente queda recogido en el Código que "no se computará para el cálculo de las legítimas", pero ninguna referencia hace sobre si deberá traerse o no a colación.

Coincidiendo con varios de los autores más cualificados en la materia, particularmente entiendo ${ }^{18}$ que la verdadera finalidad de la norma es que la donación o el legado del derecho de habitación estudiado

16 Art. 818 C.c.:"Para fijar la legítima se atenderá al valor de los bienes que quedaren a la muerte del testador, con deducción de las deudas y cargas, sin comprender entre ellas las impuestas en el testamento.

Al valor líquido de los bienes hereditarios se agregará el de las donaciones colacionables".

17 Art. 817 C.c.:"Las disposiciones testamentarias que mengüen la legítima de los herederos forzosos se reducirán, a petición de éstos, en lo que fueren inoficiosas o excesivas".

18 Entre otros, O’CALLAGHAN MUÑOZ (2000) entiende que: "No sólo no se tiene en cuenta para la computación de la donación o legado, sino tampoco para la imputación y la colación cuando los legitimarios hubiesen sido nombrados herederos"; Serrano García (2008, p. 503) recoge que: "Si bien en el 822 no se habla de dispensa de colación, creo que la finalidad de la norma exige entender que hay una presunción de dispensa de colacionar el derecho de habitación donado, si bien cabe dentro de la autonomía de voluntad del donante señalar en el negocio de atribución gratuito que la donación efectuada es colacionable"; Ruíz-Rico Ruíz Morón (2006, p. 367) considera que: "Obviamente, si la donación o el legado del derecho de habitación no se computa para el cálculo de las legítimas, tampoco será objeto de colación o imputación a los efectos del art. 1047 del C.c.". 
quede dispensado de colación, aunque la Ley no lo disponga, ya que es ésta la única forma de beneficiar realmente a la persona con discapacidad, por no servir para nada el hecho de que se dispensase de la computación si después quedan obligados a colacionarlos.

\section{Conclusiones}

No podemos negar que el efecto práctico del derecho de habitación en nuestro Ordenamiento era casi nulo. Sin embargo, el gravísimo problema de la vivienda familiar que se viene presentando en los últimos años en casos de separación o divorcio, o liquidación de sociedad de gananciales, ha generado una cierta resurrección de estos derechos reales en los últimos tiempos.

Junto a ello, debemos destacar que el derecho de habitación cada vez es más usado en nuestro sistema jurídico por el simple hecho de que en España, según el Instituto Nacional de Estadística, ${ }^{19}$ existen en la actualidad más de 3,8 millones de personas afectadas por alguna discapacidad (cerca del 10 por ciento de la población), de modo que hablamos de 3,8 millones de hogares españoles que tienen que hacer frente, de muy diversas maneras, a la discapacidad que sufre algún miembro del núcleo familiar, debido, entre otras cosas, a la mayor longevidad de la población y a las nuevas formas de discapacidad existentes.

Y precisamente con la intención de proteger patrimonialmente a las personas con discapacidad, se produjo hace años por la Ley 41/2003 la modificación radical del artículo 822 del C.c., a partir del cual, hoy en día en nuestro país los testadores con legitimarios con discapacidad podrán establecer a favor de éstos un derecho de habitación sobre la vivienda habitual, siempre y cuando ambos conviviesen en el inmueble al momento de la muerte del testador.

Pero en nuestra opinión, la importancia del artículo 822 del C.c. radica en tres puntos concretos:

$1^{\circ}$.- Que de este derecho de habitación (a diferencia de otras medidas de protección introducidas por la Ley 41/2003 que solo protegen a los descendientes con discapacidad o incapacitados) podrá beneficiarse cualquier legitimario con discapacidad del testador, entre los cuales se incluyen los padres o ascendientes, o incluso el cónyuge viudo.

$2^{\circ}$.- Que la donación o legado del derecho de habitación expuesto no se computará para el cálculo de las legítimas, o lo que es lo mismo, que el legitimario con discapacidad que se beneficie de este derecho de habitación tendrá la misma cuota de legítima que el resto de herederos.

$3^{\circ}$.- La más importante, en nuestra opinión, es que en aquellos casos en los que el testador que el testador no se haya opuesto expresamente al derecho de habitación o hubiera dispuesto otra cosa, éste se otorgará por ministerio de ley a favor de aquel legitimario con discapacidad que lo necesite, lo cual implica que en España, cualquier persona con discapacidad que ostente la condición de legitimario respecto a un testador que no haya dicho nada al respecto en su testamento, tendrá por ley derecho a habitación en el inmueble en el que convivía con el testador, siempre y cuando el legitimario con discapacidad lo necesite.

\section{Referencias}

DÍAZ ALABART, Silvia. La sustitución fideicomisaria sobre el tercio de legítima estricta a favor de hijo o descendiente incapacitado judicialmente (Art. 808 C.c., reformado por la Ley 41/2003, de 18 de Noviembre). Revista de Derecho Privado, Universidad Externado de Colombia, Bogotá, n. 5-6, p. 259270, mayo, 2004.

19 Datos obtenidos del Boletín Informativo de la del Instituto Nacional de Estadística, No 10/2009. Disponible: <http://www.ine.es/jaxi/menu.do?type =pcaxis \&path=\%2Ft15\%2Fp418\&file=inebase> 
DÍAZ ALABART, Silvia. El discapacitado y la tangibilidad de la legítima: fideicomiso, exención de colación y derecho de habitación (Ley 41/2003, de 18 de Noviembre de protección patrimonial de personas con discapacidad). Aranzadi Civil, [S.I.], n. 1, p. 2099-2133, 2006.

FUENTESECA DEGENEFFE, Cristina. Aspectos sucesorios de la Ley 41/2003, de 18 de Noviembre, de Protección Patrimonial de las personas con discapacidad y de modificación del Código civil, de la Ley de Enjuiciamiento Civil y de la Normativa Tributaria con esta finalidad. En: GONZÁLEZ PORRAS, José Manuel; MÉNDEZ GONZÁLEZ, Fernando P. (Coord.). Libro Homenaje al profesor Manuel Albaladejo García. Colegio de Registradores de la Propiedad y Mercantiles de España, Servicio de Publicaciones de la Universidad de Murcia, Murcia, v. 1, 2004, p. 1743-1762.

GÓMEZ GÁLLIGO, Francisco Javier. La sustitución fideicomisaria en la legítima estricta a favor del discapacitado. Revista Crítica de Derecho Inmobiliario, [S.I.], ano 81, n. 687, p. 11-30, enero-feb., 2005.

GONZÁLEZ PORRAS, José Manuel. Algunas cuestiones sobresalientes en la reforma del Código Civil sobre la protección de las personas discapacitadas o incapacitadas. En: Casado Raigón; Gallego Domínguez (Coord.). Personalidad y capacidad jurídicas: 74 contribuciones con motivo del XXV aniversario de la Facultad de Derecho de Córdoba. Córdoba: Universidad de Córdoba, Servicio de Publicaciones, 2005.

LEÑA FERNÁNDEZ, Rafael. Posibilidades testamentarias y otras disposiciones en materia de sucesiones que ofrece la Ley 41/2003. En: Discapacitado, patrimonio separado y legítima. Cuadernos de Derecho Judicial, Madrid, n. 20, p. 179-272, 2005.

O'CALLAGHAN MUÑOZ, Xavier; SIERRA GIL DE LA CUESTA, Ignacio (Coord.). Comentario del Código Civil. Barcelona: Bosch, 2000.

SERRANO GARCÍA, Ignacio. Protección Patrimonial de las personas con discapacidad: Tratamiento sistemático de la Ley 41/2.003. Madrid: Iustel, 2008.

VIVAS TESÓN, Inmaculada. La protección económica de la discapacidad. Barcelona: Bosch, 2009.

Recebido em: 05/09/2017

Aprovado em: 20/09/2017 